\title{
Karelian Language and Culture: a Qualitative User Study of Mobile and Web Games
}

\author{
Leena Arhippainen \\ INTERACT Research Unit \\ University of Oulu \\ Finland \\ 0000-0001-6698-9788
}

\author{
Paula Alavesa \\ Center for Ubiquitous Computing \\ University of Oulu \\ Finland \\ 0000-0003-3546-5150
}

\begin{abstract}
Revitalizing endangered minority languages is important from the perspective of preserving cultural diversity. Games and gamified application can provide ways to support learning minority languages and their dialects. We present user experience insights from a small-scale study conducted for a selection of freely available Karelian language and culture related games. By sharing our findings, we want to raise discussion about how gamification and serious games can help in revitalizing minority languages such as Karelian language. It is important to find out different ways for co-creation and cooperation in minority language also from the perspective of game development. For this study we recruited five participants, whose age varied between 4 to 72 . The reception of games depended on the previous experiences of Karelian language and personal history. We noticed that the expectations for learning games vary with different aged participants.
\end{abstract}

Keywords-Karelian language, Karelian culture, Minority languages, Revitalization, Serious games, User study

\section{INTRODUCTION}

Karelian language is classified as a highly endangered language [1] and it is divided into Karelian Proper and Olonets Karelian (Livvi Karelian). Karelian Proper is further divided into North Karelian (Viena), and South Karelian (Suvi) [2-5]. Strong actions and digital solutions are required for revitalizing Karelian language in the near future. Traditionally, formal studies, books and social interactions have been used for learning language and culture. The aim of gamification approach is to develop games from non-gaming contexts by applying game design elements for engaging players and increasing their motivation [6-8], which are key factors for increasing the effectiveness in language and culture learning. Gamification approach in educational games can improve experiences (e.g. fun) and knowledge acquisition, as an enhancement to face-to-face learning in the classroom context $[9,10]$ and increase willingness of learners to learn. Mobile or computer educational games can provide better learning environments than using only a traditional approach $[9,11,12]$.

There are not many existing web or mobile games for learning Karelian language and culture $[13,14]$. There exists online game called Riputandupučas [15] which is a hangmantype game for learning Livvi Karelian. In the game, the Karelian aplhabets are provided, and thus the player can easily

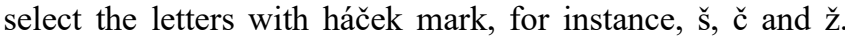
Another web games for learning Livvi Karelian can be found from the Digital Dialects platform [16], which provides easy and simple learning games for beginners with various themes, for instance, numbers, days, months, colors, foods, animals, vocabulary and phrases. Animations and audio material are utilized in the game design.
The Kielimestari [17] game is developed for learning minority languages of Finland such as Swedish, Northern Sámi and Karelian. Karelian quiz texts in the game are made in Viena Karelian. The Viena - Epic Kalevala Adventure [17] game has great visual design and sounds. It introduces a player to Karelian culture by narration, but the texts are in Finnish or English. Karelian language is not provided or taught in the game. Another visually rich mobile game is Heroes of Kalevala [19]. This game familiarizes a player to Kalevala stories and heroes, but is only in English. Any learning aspects relating to Karelian language is not provided. These two games can be seen developed more for literary tourism and culture purposes, than Karelian language learning.

The existing games are examples of an attempt to help people learn Karelian language [15-17] or culture by leveraging digital media $[18,19]$. However, more gamified applications and serious games are needed both in mobile and web platforms for different user groups. In addition, it is important to provide learning applications for both Finnish and Karelians in Finland and Russia, Republic of Karelia. In this paper, we present findings based on a qualitative smallscale user study. Our goal is to explore how Finnish speaking people with varying backgrounds receive mobile Karelian language learning games.

\section{RELATED WORK}

Games and gamification can help in creating more attractive context independent learning solutions. The target of gamification is to increase the motivation and engagement of users [20, 22]. Game elements in learning games are simpler and fewer than in entertainment games [9-11, 23]. In an ideal situation they are based on best pedagogical practices, while game design elements can be shown as levels, progress status, and score [6].

\section{A. Accessibility and Ease of Use}

Even simple entertainment games are saturated with language and known to enable unintentional language learning [21]. In educational games learning can happen while playing the games with interesting and attractive playthroughs. Educational games concentrate on engagement, simpler features, gameplay, and learning activities [10, 20], which increase the willingness of players to learn and the effectiveness of knowledge acquisition. Educational games should be easy to play and focus on the educational aspects rather than social interactions that can be the goal of pure entertainment games [24]. However, in the context of minority languages the revitalization is an important target and this target cannot be achieved by ignoring the social aspects [25]. 
Accessibility of the learning tools becomens relevant when different age-groups are brought together [23].

Research on the effectiveness of educational games for English learning shows better knowledge acquisition and improve listening, reading, and writing skills [26]. Moreover, those skills can be complemented with video and audio materials to increase the effectiveness of learning, rather than by using only written texts [9]. It is important to notice that skills such as listening, reading, writing, and speaking can be taught with language learning games $[27,28]$. Games can be untiring tutors and computers can provide repetitive and targeted feedback, regardless of time and location, which can be especially useful for grammar and vocabulary learning [21].

\section{B. Digital Games in Karelian Context}

Games for learning Karelian language are difficult to find. Online games called Riputandupučas [15] and Digital Dialects games [16] are found and they focus on learning Livvi Karelian. Digital Dialects platform provide several minigames with various languages and themes. Audio and visual fetaures helps beginners to hear pronunciation especially words with $\breve{s}$, $\check{c}$ and ž letters.

A mobile game called Kielimestari [17] supports learning Viena Karelian. There are also some games developed for introducing about the Finnish national epic the Kalevala such as Heroes of Kalevala [19], Viena - Epic Kalevala Adventure [18] and the Kalevala application [30], which include Kalevala runes (cantos) as a text format. However, these Kalevala related games and applications are not enough for learning Karelian language. For instance the Kalevala application is only in Finnish, not in Karelian, even though the Kalevala is published in Viena Karelian [31].

\section{EVALUATION}

This chapter presents the study process and methods for evaluation of distinct games. Our focus is on comprehensive experiences and we wanted to understand the player as a new learner of Karelian language.

\section{A. Participants}

We are spesifically interested in the value of social aspects has on revitalization efforts. Mixing players with different backgrounds and skills can benefit the revitalization. Therefore, we recruited five users from different age groups (from 4 to 72 years). We had two girls between 4-6 years (ID23 ), two boys between 11-15 years (ID5 and ID4) and one senior male (ID1). In the study the age limit and ability to read were taken into account and in those part the gameplay and game walkthroughs focused for instance on visual issues and game ideas and wishes. We wanted to understand player needs, learning motivation and culture interest in order to find out how the gamification approach could help to revitalize language and provide solutions to transfer language knowledge thought generations. Therefore, all participants were relatives with each other. We wanted to observe player experience between family members and study co-experience of gaming and language learning.

All participants were beginner learners in Viena Karelian. The senior male had studied Viena Karelian in a club for over a year. The three youngest participants (ID2, ID3 and ID5) had learned some Viena words in their Viena related hobbies by singing, playing, or acting. However, during the COVID-19 situation, these hobby events had been cancelled since of spring 2020. According to participants' own estimation, they could understand Viena Karelian based on the Finnish language and they knew some basic words or could formulate simple sentences. They did not have prior skills of writing or speaking Livvi Karelian, which is more difficult to understand based on Finnish. However, they knew that Livvi is one dialect of Karelian language.

\section{B. Evaluation Setup}

and game walkthroughs. The process of the evaluation is depicted in the Fig 1. The findings from the Study I are reported in the paper $(\mathrm{P} 1)$ [32]. In this paper we concentrate on our qualitative findings based on the five games (Fig. 1, P2).

Each test took from one to two hours. The Study II was organized on another day and it included co-located and collaborative playing sessions as well. Mobile applications for Android OS; Viena - epic Kalevala Adventure [17], Kielimestari [17], Heroes of Kalevala [19], Kalevala Application [30] were tested from mobile phone and Digital Dialects Karelian [16] web games from a laptop because it did not properly scale for mobile phone use. We have not been involved in developing any of these five games. Even though the mobile applications [17, 19, 30] were not designed as language learning purposes, we wanted to show them to the participants because they are relatively new, and provided culture and minority language knowledge for players. Also, their audio-visual design was more advanced than in our games (Fig. 1, Study 1: phases 2-5) and we wanted to extend the sample of games towards entertainment games too, to explore the value of these games for learners. Therefore, we thought that these games could provide a fruitfull basis for discussion and playful game design session.

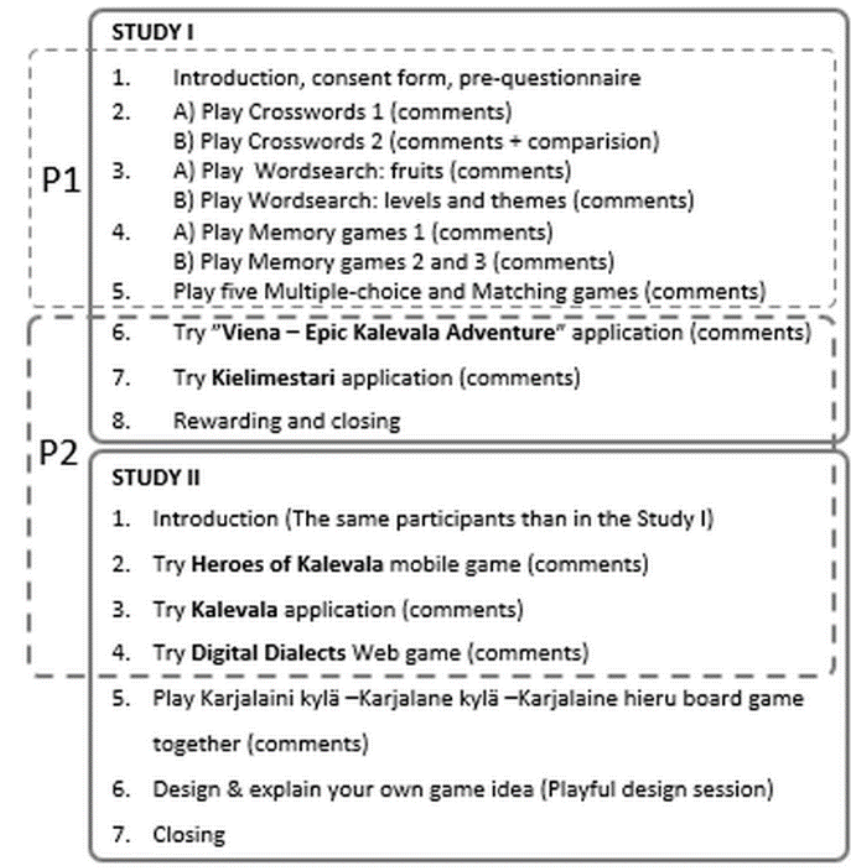

Fig. 1. Five games evaluated and discussed in the this Paper (P2). 


\section{Viena Epic Kalevala Adventure Game}

This game introduces a player to Viena and the mythical world of Kalevala by a narrative and audiovisual story [17]. The Hero character in the game is helped by the old and wise sage Uljaska. The fact that the Uljaska has been the apprentice of the Väinämöinen of the Kalevala, gives to a player real information of history and culture. The main features in the game are: 1) "Follow along the epic narrative in the story sections", 2) "Solve puzzles in the spell game", 3) "Make narrative choices in the dialogue choice sections" and 4) "Travel across Viena in the map screen" [17].

Before the test, we did not introduce too much of the game to the users. We were interested in seeing how the participants perceived the games and which aspects they liked or disliked. Spesifically, our aim was to investigate how some of these games could be utilized in language and culture learning and revitalization.

The participants were impressed by the audiovisual design (Fig. 2A-E). Of course, it is important to notice that the participants used this game after testing the other simpler games (Fig. 1, Study 1: phases 2-5). For instance, one player (ID5) said immediately after starting to play the game: "I' $m$ already now impressed. Looks pretty good. This is cool". When he noticed that there is quite a long story to read, he commented: "These texts could be read aloud, because I usually do not read texts in games. I would prefer to listen to these long sentences" (ID5). He also commented that the game is more like digital storytelling. Also, the player (ID1) perceived the game as a form of digital storytelling, a fairytale or a book, not a game. Based on their gameplay, the participants were not sure if the story was totally true, partially true or totally fictitious.

The senior player (ID1) was interested in the story. He read all lengthy texts and was curious to learn and understand more. He was interested in karelian culture and language. Also he was not so experienced mobile player, so he was exploring the game under evaluation carefully. Instead the younger player (ID5) wanted to continue playing because he wanted to see what kind of game this is and what minigames had been implemented (e.g. spelling game). However, he perceived the long text inserts boring, just like the other young player (ID4).

The participants understood the feature of narrative choices quite easily from the small arrow (Fig. 2C). However, all the users would have needed a short tutorial or information about what is the point in the game and how to play it or the playing time should have just been longer.

The young participants understood easily and fast how to interact with the spelling game. However, the senior participant (ID1) was not able to use it without moderator's help. When he understood how to drag and drop pieces, he was impressed and was able to finish the puzzle. However, the spelling text on the screen was so small and in handwriting style that he started to blame his glasses: "I think my glasses are so poor and old that I cannot read it" (ID1). It was not possible to zoom the text. However, he continued playing without figuring out the purpose or message of the spelling game.

When the senior participant (ID1) used the map, at first he did not understand how to use it. When he was encouraged to
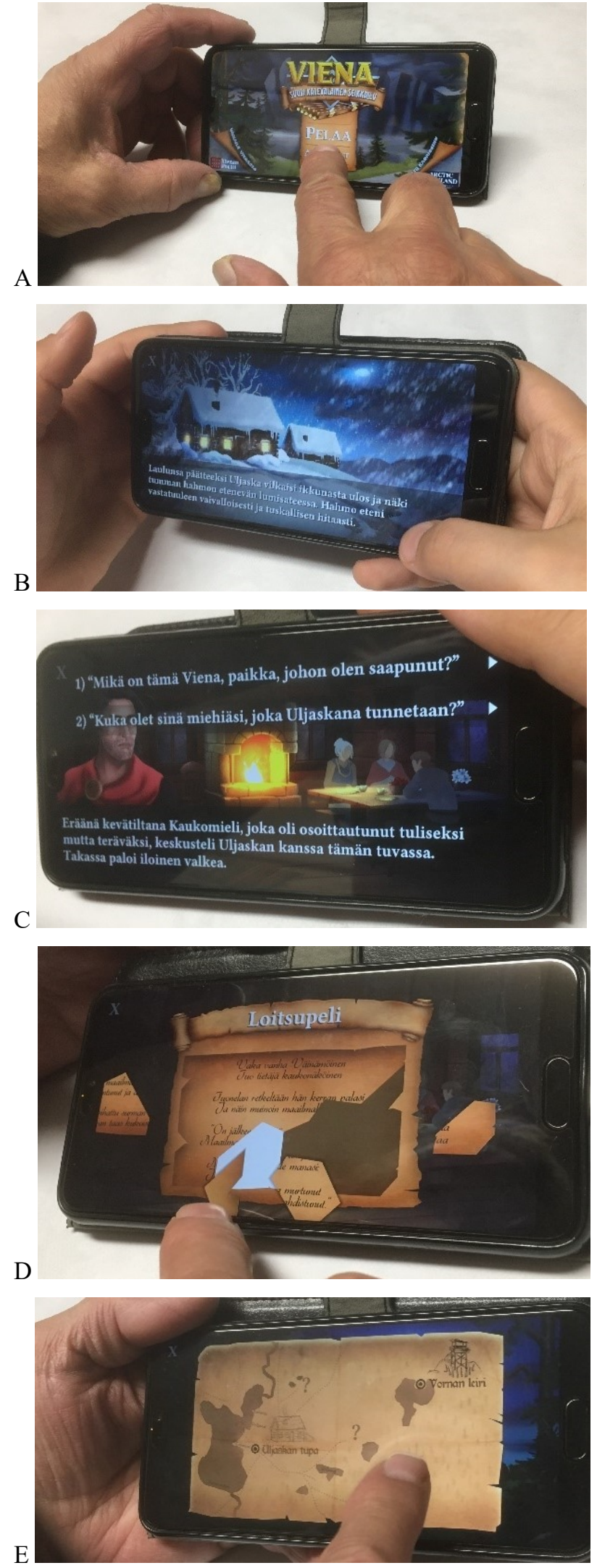

Fig. 2. Participants tested the Viena -Epic Adventure Game.

try something, he tapped the different objects on the map, but was not really able to select the highlighted object (e.g. Vornan leiri) (Fig. 2E). Maybe the interactive area was too small for him or he did not notice the highlight. It is notable that the game (Fig. 2.) does not use accessible colour palette. 
The adolescent player (ID4) did not perceive this application as a game. He did not read the long stories, instead he tapped the arrow quickly to continue until the story was over and something new appeared on the screen. He approached the game as it were just a simple puzzle. Likewise, the other players (ID1 and ID5) did not perceive what they were doing as gameplay. The senior participant (ID1) regarded it as a narrative and was interested in it because of the cultural aspects. The younger participant (ID5) would have wanted to "walk in the $3 D$ environment and have adventures in it", for instance, collect some items, which are in Viena Karelian. He said that he would like to learn Viena Karelian language by playing interesting games in Viena Karelian. Unfortunately, this game was implemented only in Finnish and English. However, this is quite recently published game (September 2020) [33] and developed in three months [34], thus there may be future updates and localization of the game also for instance for Karelian and Russian.

\section{The Kielimestari Games}

Kielimestari [17] is developed for Android OS platforms. The aim of the application is to teach about the minority languages of Finland: Swedish, Karelian and Northern Sámi. In this game the Karelian text examples are written in Viena Karelian. The game was selected for the evaluation, because it included this aspect of language learning.

After selecting the language area from a map of Finland (Fig. 3A), the game provides different themes, for instance, sports, games, animals, traveling, movies and literature (Fig. 3B). When the senior participant (ID1) started the game, he did not really understand the point of it. He read the given sentences and selected one from the four options (grey buttons). For instance, the fig. 3C shows one example, where the sentence is in Karelian language. The red capital lettered text 'SUOMALAISET' was quite similar than the option he selected, except the word 'šuomelaiset' was written with š letter and first ' $a$ ' was 'e'. However, the word was quite similar. This person understood the idea of the game only after when the moderator asked to select markers from the map. Then he could play the game also with Swedish and Northern Sámi sentence examples and see more differences between sentence and the given options. For instance the Northen Sámi is so different from the Finnish language that the idea of the 'translation' quiz game is easier to understand. The younger participants (ID4, ID5) understood the game logic easily because they had prior exprience of using Kahoot, but they were not really interested in reading the sentences as the participant (ID5) commented: "I just read the red word and select based on that. I don 't read the whole thing". The senior participant (ID1) was again more interested in the content.

Because Karelian is so closed to Finnish language, some examples can be too easy. However, sometimes, this is an ambivalent issue, because the similarity in the language does not always help. For instance, the player can start to think that there is a riddle or a dilemma in the example, and he/she may think that selecting the obvious Finnish word is too obvious option. Likewise, sometimes there can be several similar words in Finnish but only one right word in Karelian. The fig. 3D shows an example where the player (ID5) selected first the wrong option and when it was highlighted with red, he selected the right option, which was in fact the same in Finnish and Karelian. (Fig. 3D)

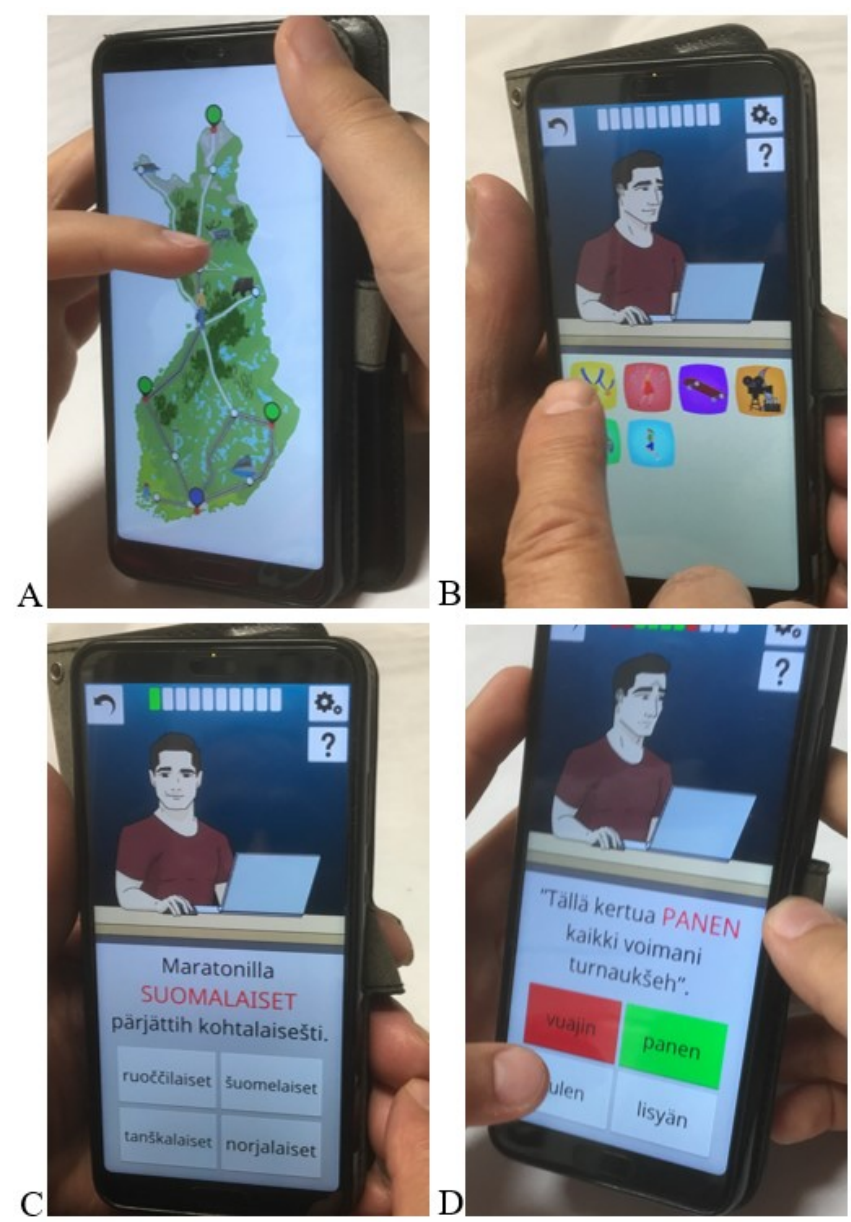

Fig. 3. Participants tested the Kielimestari game.

The participants perceived also this game visually pleasing. The audio of the game was quite neutral, and it could be switched off. Also, the player character was quite neutral: a male studying or working. However, it was interesting to notice that the 6-year-old girl (ID 3) would have liked to change that for a female (girl) character.

The adolescent participant (ID4) did not like this much because it "was like a school thing" and signified that the game is for learning, not entertainment. On the other hand he said that, for instance, Kahoot-type quiz is nicer because then you can compete with school mates.

\section{E. Heroes of Kalevala Game}

The Heroes of Kalevala was selected for the evaluation, because it provides visually rich game experience and Karelian culture information in a form of Kalevala stories and characters. The game could be characterized as a simplified strategy game. In the game a player can earn coins and complete levels by playing tile-matching game. When a player has enough coins he/she can buy different items for their village and thus increase villagers happiness (Fig. 4B). The game includes eight different heroes (Fig. 4A) and four villages (Untamola, Tapiola, Pohyola, Tuonela). Each hero has their own unique power and a player can select the hero for each game battle (Fig. 4A) Väinämöinen is the most know 
hero of the Kalevala and his chant produces poweful notes that will destroy similar items in a battle (Fig. 4C).
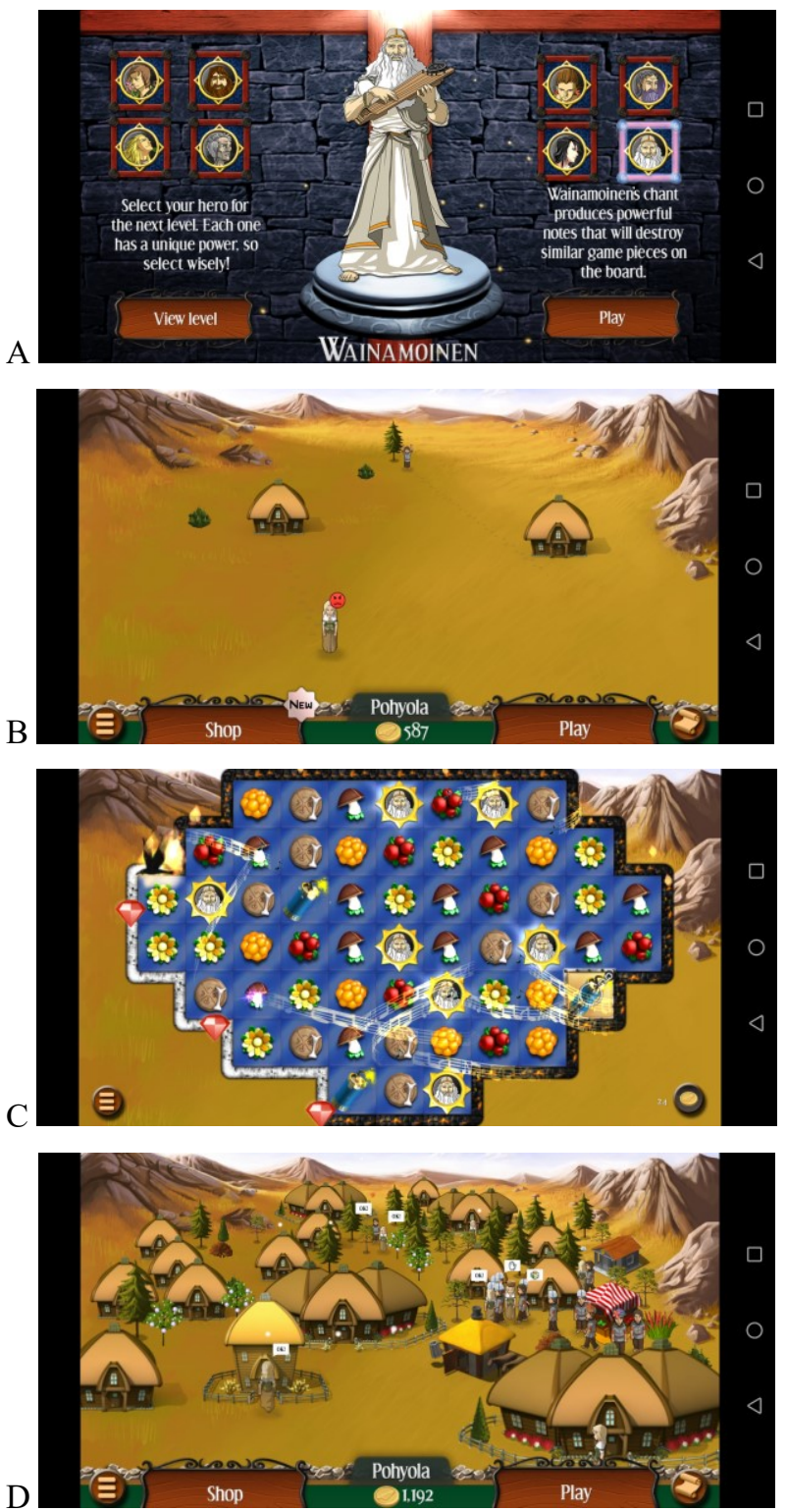

Fig. 4. Screenshots of the Heroes of Kalevala game.

The game includes over 140 [19] levels where in each level a players' task is to match three similar items for breaking the tiles. The content of the match varies according to villages which increases possible gameplay combinations and enhances player experience. When playing the game in the first levels in the first villages, the items are for instance, berries, flowers and pine cones (Fig. 4C). In the last village, Tuonela, items are bones, skulls and beetles. From the language learning perspective the game could include text or voice about the items in Viena Karelian.

Participants (ID3, ID5) first liked the battle game, but it became repetitive and boring, because there was not enough variation in the game (e.g. battles and villages). The participant (ID5) would have like to see more villages and he though that their size was too small in the current version, which was only what fit on screen view. He proposed that there should be more creative aspects as well so that he could invent, build and make decisions with conequences. The adolescent participant (ID4) did not like this type of game at all and he commented that this battle system is a copy from Candy Crush Saga game. For senior participant (ID1) it took some time to understand the game logic because he really did not have prior playing experience with mobile games. Also texts were only in English and thus he needed help with the translation. After playing alone, for a while, the game was also played together by the grandfather (ID1) and a grandchild (ID3).

From language and culture knowledge learning and sharing point of views it could be important to provide games which can be used together. Younger players can guide the older players who can in turn share their culture and life experiences. Co-located gameplay could provide better language learning and playing experiences and minimaze the game experience gap between generations (e.g. traditional indoor/outdoor games vs. video games).

Participants liked the visual design of the game and expecially animations on the battle mode. The score was characterized boring by the participant (ID5). He would have like more variations for the game music and audio effects. He liked when audio turned a bit more scary when time was near to end on the battle mode.

Participants liked that there were difference heroes with various powers and the participant (ID5) proposed that there could be even more characters. He liked 'Väinämöinen' and 'Ahti' heroes, because their powers "felt the best" (ID5). When the moderator asked that did you learn something from the epic of Kalevala he said that: "Yes, the heroes" (ID5).

\section{F. Kalevala Mobile Application}

Kalevala Mobile application was selected for the evaluation, because we wanted to see how the rune content was provided in the application and how participants would perceive it.
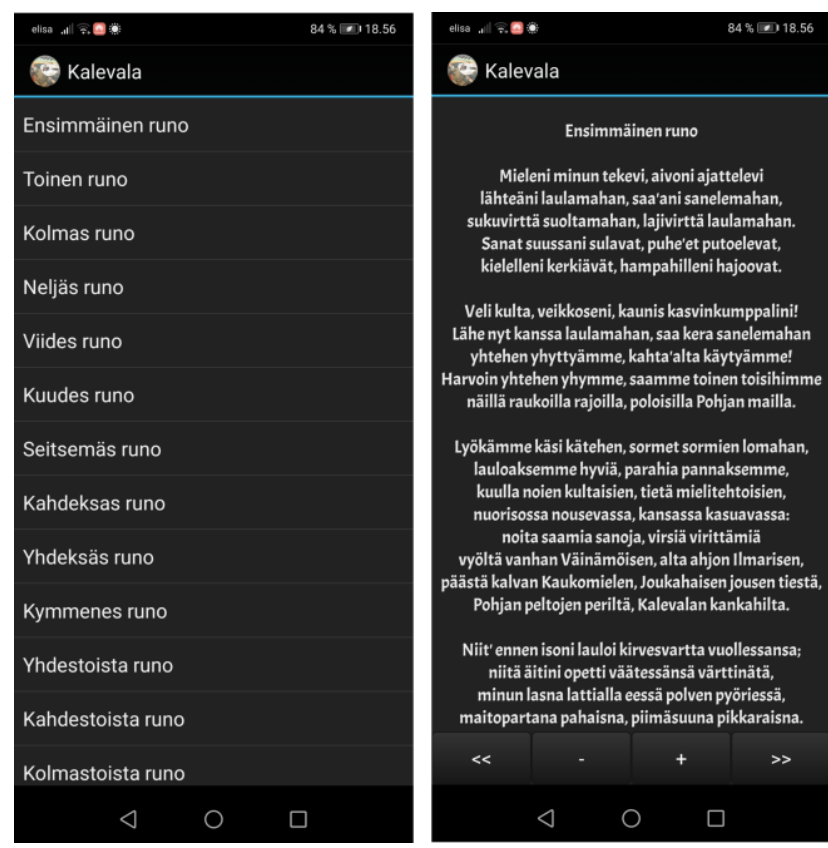

Fig. 5. Screenshots of the Kalevala application. 
The application include 50 runes (cantos) from the Kalevala epic in text format (Fig. 5). It is important to have these runes in a digital and mobile format. However, from the language learning point of views, it would be important to utilize this material for learning for instance the application could include translations and image content as well. Current version is only in Finnish, not in Viena Karelian.

All young participants perceived this application as boring because it was jus text without any audiovisual content. The participant (ID5) noticed that text is in kalevala rune metre (he said that he has learned this at school few months ago) and he proposed that it would be good to have the text in audio, so he could learn rune metre by listening to it.

The senior participant (ID1) was interested in this application and thought that it would be easy to just read Kalevala from the phone. He commented also, that this type of application is good for those who are interested in Kalevala and Karelian culture. He began to contemplate what kind applications or games could be so that they would be interesting also for those do not have any knowledge or ancestors in the Republic of Karelia.

\section{G. Digital Dialects Online Language Learning Games}

This game was selected for the evaluation, because it included several small games for learning basics of Livvi Karelian with audiovisual effects. When revitalizing Karelian language one needs to take into account all its dialects, therefore we included this game into our selection. The game was liked by the participants, because this had more variations in game tasks and audio was perceived important when playing language learning game. Based on observations leaning Livvi was fun, because some of the words were so weird, for intance, the participant (ID5) laughed a lot when he first heard word 'maksankarvaine' which is ruskea (brown) on Finnish. This word was funny because 'maksa' (liver) and 'karvainen' (hairy) has totally different meaning in Finnish than 'brown'.

The youngest participants (ID2-3) liked this game, for instance the youngest participant (ID2) said: "Awesome". They wanted to play especially 'Food \& drinks' and 'Fruit \& vegetables' games (Fig. 6) several times and they learned easily new Livvi words. For instance they learned onion (sipuli in Finnish) which is 'laukku' in Livvi Karelian. 'Laukku' in Finnish is a bag, and thus the word has totally different meaning in Finnish. Also, they learned quite fast that an egg (kananmuna in Finnish) is 'jäiččy' in Livvi. 'Jäiččy' word has not any similar pronunciation or meaning in Finnish.

Eventhough participants liked this game, it was also perveiced a bit old-fashioned because of its visual design and how interactions were indicated. Also the participant (ID5) commented colours on the front page, where the background was white. He noticed that even thought the front page was full screen, the mini games were always shown smaller in the left top (Fig. 6B), so the mini games did not scale to full screen and they could not be manipulated either. He would have prefered a full screen view when playing. The senior participants (ID1) was very surprised and happy about the game. When the moderator introduced the game portal to him, he was really impressed that this type of language portal is available for so many languages.
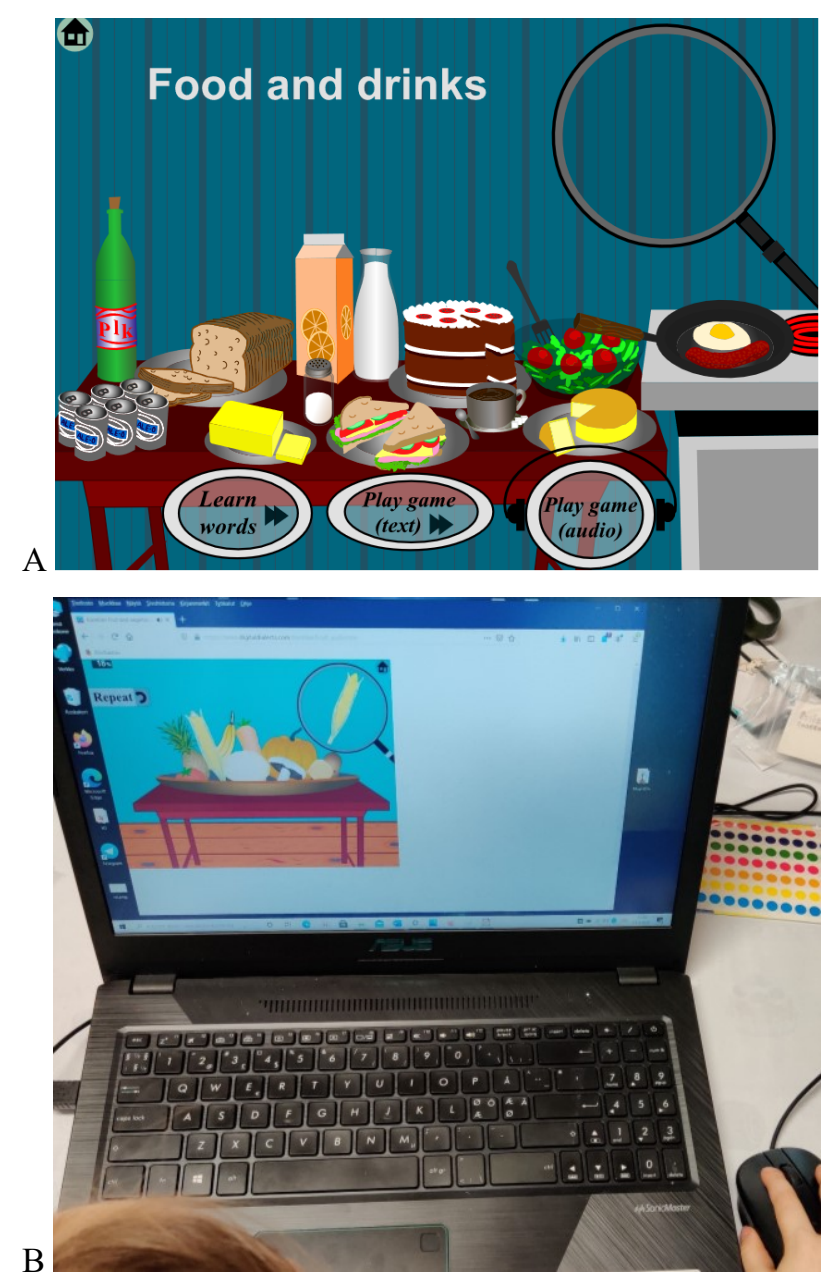

Fig. 6. A) Screenshot of the Digital Dialect Karelian's Food and Drinks game and B) the participant (ID2) playing its Fruit and vegetables game.

The website provides interactive games for learning 80 foreing languages and it is implemented for independent language learning and for classroom use [36]. The senior participants (ID5) commented that this type of learning games could be good for lonely people or those who cannot attend on-site courses.

\section{FINDINGS AND DISCUSSION}

In this paper we present details of how Finnish beginner Karelian learners perceive different mobile and web games which contain elements of Karelian language or culture. The games and applications selected for this evaluation indicate that there is interest to develop games for teaching and experiencing Karelian culture, especially Kalevala related topics. However, there is a need to develop games also for leaninng and maintaining Karelian language. The digital solutions should be designed for different age groups (children, adolescents, adults, and seniors) with various language backgrounds (e.g. Finnish, Karelian and Russian). Despite the importance of social aspects of gameplay to revitalization [25], the games should also provide locationindependent solutions for self-studying.

In this study, only the Kielimestari application [17] and Digital Dialect website [16, 36] provide language learning possibilities. Our participants wished that games should be 
implemented in Karelian language and thus learning would happened unintentionally while playing [21].

According to our findings we identified the following points to consider when developing games in minority language context:

- A possibility to listen (native) language is crucial for games relating to minority language context [9].

- In addition to English, the game content should be available also in the target minority language.

- It is important to provide good and interesting visual design both from usability (e.g. indications for interaction, size and style of fonts, contrast) and aesthetic perspectives (e.g. pleasurable, modern, culturally appropriate) [23].

- Visual elements such as animations are important both from usability and player experience perspectives (e.g. entertaining, engaging).

- Game should allow creative elements for player to make decisions and build their own game environment. None of our example games did this to full extend, and it was mentioned by the players especially in the case of Heroes of Kalevala.

- When implementing cultural features in a learning game, a player should be able to distinguish is the content (e.g. narration, characters, venue) fictive or factual.

- A short and easily understandable tutorial is important to be available.

- It is important to develop minority language related games also for a wider audience. For instance, only Kalevala related games are not enough.

Our findings are not conclusive, there must be other factors that influence learning outcomes in games. In addition, we cannot prioritize any of these factors yet based on the current study. However, by sharing the findings of this study, we wish to raise discussion about how games could help in revitalizing minority languages such as Karelian. For language preservation and revival, it is important to understand the reception of these games with wide audience, for instance, player who has not any Karelian culture, language or ancestral background. This may also be a key factor in bringing learners together.

\section{A. Limitations and Future Work}

We acknowledge that our sample size is small. Due the COVID-19 pandemic restrictions during 2020-2021 we were not able to conduct a bigger on-site evaluations. We did not regard online testing as a proper approach for this type of evaluation, where we have young and senior participants and we want to observe co-playing experiences. In addition, we acknowledge that we cannot generalize our findings, which was not intended in this case. Our aim was to gain better understanding of perceptions and ideas from the beginner Karelian learners. In the future, we would like to involve more participants and have a bigger sample from all age groups. Also, it would be interesting to conduct more family studies where several generations play and experience games together. Families could be mixed according to age groups and
Karelian language skills. This might help us map the features required to bring different aged language learners togeather for optimal revitalization. It is known that if revitalization is considered outside the social context it cannot happen to the full extend. Without social contracts and interactions, i.e. sociolinguistic context, influencing the process the revitalization is not complete [25].

\section{CONCLUSION}

This paper presents findings from a qualitative user study where five participants played and familiarized with five Karelian language and culture related mobile and web games or applications. In the study we were interested to observe how the participants perceive the games and what ideas or wishes they would have for future game design especially from the perspective of language learning. The reception of games depended on the previous experiences of Karelian language and personal history. Especially the elder player was interested in culture knowledge and learning language easily by training and repeating games. For the younger players the entertainment and creative aspects were more important, for instance, they were interested in building the environment and customise the avatar. Participants wished for the learning to be more unintentional, for instance, facilitated by reading and hearing the Karelian language while playing. All participants were interested in playing games which related to various topics, not only Kalevala. Audio-visual design, usability and overal experience are important to take into account when developing games for revitalizing minority languages. We can conclude that games should be accessible and engage users to play, experience and learn.

Due to the small sample our findings are inconclusive. However, from the perspective of language revitalizations it is important to develop games in Karelian language. By sharing these findings, we want to raise the discussion about how gamification and serious games could help in revitalizing minority languages such as Karelian. It is important to find out different ways for co-creation and co-operation in minority language game design and development.

\section{ACKNOWLEDGMENT}

The second author has received funding from Business Finland funded project Reboot Finland IoT Factory $33 / 31 / 2018$, supported by Academy of Finland 6Genesis Flagship (318927). The authors would like to thank all participants for their valuable feedback. Special thanks to the game and application designers and developers for their great effort for revitalizing Karelian language and culture.

\section{REFERENCES}

[1] A. Sarhimaa, "Karjalan kieli Suomessa: ELDIA projektin tuloksia". Studies in European Language Diversity 27.1. 2016.

[2] Y. Klementyev, S. Kovaleva, and K. Zamyatin, "The karelian language in russia: An overview of a language in context," Working Papers in European Language Diversity, 12.) Helsinki: ELDIA , Tech. Rep., 2013.

[3] T. Salonen, "Karelian a digital language?" The Digital Language Diversity Project, Tech. Rep., 2017.

[4] A. Sarhimaa, "The karelian language in finland: An overview of a language in context," Working Papers in European Language Diversity, Tech. Rep., 2011. 
[5] Kotimaisten Kielten Keskus. Retrieved $12^{\text {th }}$ September 2019, from: https://www.kotus.fi/kotus. 2019.

[6] S. Deterding, "Gamification: designing for motivation," interactions, vol. 19, no. 4, pp. 14-17, 2012.

[7] S. Deterding, R. Khaled, L. E. Nacke, and D. Dixon, "Gamification: Toward a definition," in CHI 2011 gamification workshop proceedings, vol. 12. Vancouver BC, Canada, 2011.

[8] J. Hamari, J. Koivisto, and H. Sarsa, "Does gamification work?--a literature review of empirical studies on gamification," in the 47th Hawaii international conference on system sciences (HICSS), 2014 pp. 3025-3034, doi: 10.1109/HICSS.2014.377.

[9] P. Backlund and M. Hendrix, "Educational games-are they worth the effort? a literature survey of the effectiveness of serious games," in Games and virtual worlds for serious applications (VS-GAMES), 2013 5th international conference on. IEEE, 2013, pp. 1-8.

[10] E. A. Boyle, T. Hainey, T. M. Connolly, G. Gray, J. Earp, M. Ott, T. Lim, M. Ninaus, C. Ribeiro, and J. Pereira, "An update to the systematic literature review of empirical evidence of the impacts and outcomes of computer games and serious games," Computers \& Education, vol. 94, pp. 178-192, 2016.

[11] R. E. Ferdig, Handbook of Research on Effective Electronic Gaming in Education. IGI Global, 2009.

[12] H. W. Giessen, "Serious games effects: an overview," Procedia-Social and Behavioral Sciences, vol. 174, pp. 2240-2244, 2015.

[13] J-P., Koski and L. Arhippainen, Ukko opaštau lapšie äijän-Serious games as tools for teaching Viena Karelian to Finns?. In The 25nd Conference of Open Innovations Association FRUCT, Helsinki, Finland. 2019, pp. 5-8.

[14] Triando and L. Arhippainen, "Development and User Experiences of the Learn Viena Karelian Mobile Web Game". 2019 International Conference on Advanced Computer Science and information Systems (ICACSIS), Bali, Indonesia, 2019, pp. 465-470, doi: 10.1109/ICACSIS47736.2019.8979925.

[15] Riputandupačas $\quad$ Retrived $14^{\text {th }} \quad$ September 2019 from https://opastajat.net/opastus/hangman/index.html

[16] Digital Dialects Language Learning https://www.digitaldialects.com/Karelian.htm

[17] Kielimestari application designed by the Northern Sociolinguistic Encounters. Retrieved $16^{\text {th }}$ September 2019 from https://apkpure.com/kielimestari/com.rsg.opikielta

[18] Viena: Epic Kalevala Adventure (Version 1.0.1) Retrieved 1.10.2020 from https://play.google.com/store/apps/details?id=com.RadicalRedGames. Viena\&hl=en_US 1.10.2020.

[19] 10tons. Heroes of Kalevala. 2017. Retrieved 2.8.2020 from http://www.10tons.com/Game/heroes_of_kalevala

[20] K. M. Kapp, The gamification of learning and instruction: game-based methods and strategies for training and education. John Wiley \& Sons, 2012.

[21] J. Reinhardt and S. Thorne, "Metaphors for digital games and language learning," in The Routledge handbook of language learning and technology, F. Farr and L. Murray, Eds. 2016, pp. 415-430.
[22] B. H. Sørensen and B. Meyer, "Serious games in language learning and teaching-a theoretical perspective," in DiGRA Conference, 2007.

[23] P. Alavesa and L. Arhippainen, "A Game Palette and Guidelines for Game Development for Minority Languages-Case Karelian." in DiGRA Conference, 2020

[24] C. Heeter, C. K. Chu, A. Maniar, B. Winn, P. Mishra, R. Egidio, L. Portwood-Stacer et al., "Comparing 14 plus 2 forms of fun (and learning and gender issues) in commercial versus educational space exploration digital games," in International Digital Games Research conference, 2003, pp. 4-6.

[25] A. Jaffe, "Minority language learning and communicative competence: Models of identity and participation in Corsican adult language courses," Language \& Communication, vol. 33, no. 4, pp. 450-462, 2013.

[26] S. Suh, S. W. Kim, and N. J. Kim, "Effectiveness of mmorpg-based instruction in elementary english education in korea," Journal of computer assisted learning, vol. 26, no. 5, pp. 370-378, 2010.

[27] G. Stanley and K. Mawer, "Language learners \& computer games: From," TESL-EJ, vol. 11, no. 4, p. n4, 2008.

[28] P. Wouters, E. D. Van der Spek, and H. Van Oostendorp, "Current practices in serious game research: A review from a learning outcomes perspective," in Games-based learning advancements for multisensory human computer interfaces: techniques and effective practices. IGI Global, 2009, pp. 232-250.

[29] Ekapeli Alku (n.d.) Niilo Mäki Säätiö. Google Play. Web: https://play.google.com/store/apps/details?id=fi.ekapeli.EkapeliAlku $\& \mathrm{hl}=\mathrm{fi}$

[30] Animated Oak Entertainment Ltd. Kalevala. 1.0 version. (2014) https://play.google.com/store/apps/details?id=com.aoe.kalevala\&hl=e $\mathrm{n} \& \mathrm{gl}=\mathrm{US}$

[31] E. Lönnrot \& R. Remsujeva. Kal'evala vienankarjalakši, Karjalan Sivistysseura ry, 2015.

[32] L. Arhippainen \& P. Alavesa (2021) Designing Learning Games and Tools for Karelian Language - Considerations Based on Beginners' Experiences of Gameplay. In the 28th Conference of Open Innovations Association (FRUCT), Moscow, Russia, 2021, pp. 3-14, doi: 10.23919/FRUCT50888.2021.9347578.

[33] Launch of 'VIENA - Epic Kalevala Adventure' in Kainuu, Finland. Spot-lit. Retrieved 1.10.2020 from: https://www.spot-lit.eu/launch-ofthe-new-kalevala-adventure-game-in-kainuu-finland/

[34] Artstation. H. Piirainen. Retrieved 30.11.2020 from https://www.artstation.com/artwork/Kra9BR

[35] K. Malterud, V. D. Siersma, ja A. D. Guassora, "Sample Size in Qualitative Interview Studies: Guided by Information Power", Qualitative Health Research, vsk. 26, nro 13, ss. 1753-1760, 2016, doi: $10.1177 / 1049732315617444$.

[36] Digital Dialects (2021) Retrieved 15.4.2021 from: https://www.digitaldialects.com/ 